\title{
BMJ Open A Study Investigating Markers in PLeural Effusion (SIMPLE): a prospective and double-blind diagnostic study
}

Yan-Qiu Han, ${ }^{1}$ Li Yan, ${ }^{2}$ Peng Li, ${ }^{1}$ Lei Zhang, ${ }^{1}$ Pei-Heng Ouyang, ${ }^{1}$ Zhi-De Hu ${ }^{\oplus}$

To cite: Han Y-Q, Yan L, Li P, et al. A Study Investigating Markers in PLeural Effusion (SIMPLE): a prospective and double-blind diagnostic study. BMJ Open 2019;9:e027287. doi:10.1136/ bmjopen-2018-027287

- Prepublication history for this paper is available online. To view these files, please visit the journal online (http://dx.doi. org/10.1136/bmjopen-2018027287).

Received 21 October 2018 Revised 10 May 2019 Accepted 3 July 2019
A) Check for updates

(C) Author(s) (or their employer(s)) 2019. Re-use permitted under CC BY-NC. No commercial re-use. See rights and permissions. Published by BMJ.

${ }^{1}$ Department of Laboratory Medicine, The Affiliated Hospital of Inner Mongolia Medical University, Hohhot, China ${ }^{2}$ Department of Respiratory and Critical Care Medicine, The Affiliated Hospital of Inner Mongolia Medical University, Hohhot, China

Correspondence to

Dr Zhi-De Hu; hzdlj81@163.com

\section{ABSTRACT}

Introduction Serum and fluid laboratory markers are valuable for exploring the aetiologies of pleural effusion (PE) because of their relative non-invasiveness, low cost, objective result and short turnaround time. The diagnostic accuracy of these potential markers needs to be rigorously evaluated before their widespread application in clinical practice. Here, we plan to perform a Study Investigating Markers in PLeural Effusion (SIMPLE).

Methods and analysis This is a prospective and doubleblind clinical trial which is being performed at the Affiliated Hospital of Inner Mongolia Medical University, China. Adult patients admitted for the evaluation of aetiology of PE from September 2018 to July 2021 will be enrolled after informed consent. Pleural fluid and serum specimens will be collected and stored at $-80^{\circ} \mathrm{C}$ for the laboratory analysis. The final diagnosis will be concurred with further imaging, microbiology, cytology and biopsy if needed. The results of investigated laboratory markers will be unknown to the clinicians who will make diagnosis and the clinical diagnoses will be unknown to the laboratory technicians who will determine markers. The diagnostic accuracy of investigated markers will be assessed using receiver operating characteristics (ROC) curve analysis, multivariable logistic regression model, decision curve analysis (DCA), net reclassification index (NRI) and integrated discriminatory index (IDI).

Ethics and Dissemination The study is approved by the Ethic Committee of the Affiliated Hospital of Inner Mongolia Medical University (NO: 2018011). The results of SIMPLE will be submitted to international scientific peerreviewed journals or conferences in laboratory medicine or respiratory medicine, thoracic diseases.

Trial registration number Chinese Clinical Trial Registry (ChiCTR1800017449); Pre-results.

\section{INTRODUCTION}

Pleural effusion (PE) is a frequent problem in the clinical practice and can be caused by various disorders such as congestive heart failure (CHF), liver and pancreatic diseases, diseases of lungs such as malignancy, tuberculosis and pneumonia. ${ }^{12}$ An accurate and timely diagnosis is a prerequisite for $\mathrm{PE}$ management to evaluate its cause. Light's
Strengths and limitations of this study

- A prospectively designed trial evaluating the diagnostic value of pleural fluid and serum markers in subjects with pleural effusion.

- Double-blind: the clinicians making diagnosis will be masked to the laboratory results of markers, and the laboratory technician determining markers will be masked to the clinical diagnosis of the subjects.

- Multiple laboratory markers for various target diseases will be studied.

- Multiple differential diagnosis will be considered.

- The main limitation of the study is single-centre design and there is a possibility of patients selection bias.

criteria, which encompass serum and pleural fluid biochemical analyses, are commonly used in the clinical practice to distinguish between the exudative and transudative PEs. ${ }^{3}$ Although Light's criteria has high sensitivity for detecting exudative PE, occasionally it cannot be used to differentiate the underlying causes such as infections and malignancies. ${ }^{4}$ Currently, several tools are available for exploring the aetiology of PE, including thoracoscopy, chest imaging especially CT scan, cytology and bacterial culture. ${ }^{56}$ Thoracoscopy is one of the most widely used and has a good diagnostic performance for various thoracic disorders. Nevertheless, a previous study indicated that approximately $7 \%$ of patients with PE remain undiagnosed after thoracoscopy. ${ }^{2}$ Besides, thoracoscopy is an invasive tool associated with procedure-related complications. The microbiological and cytological examinations have high specificity but their diagnostic sensitivities are unsatisfactory. ${ }^{7-10}$ Besides, the diagnostic accuracy of these tools is largely operator and pathologist dependent. ${ }^{11}$ Bacterial culture has high diagnostic specificity for infectious causes of PE; 
however, the long turnaround time (TAT) limits its application in clinical setting.

By contrast, serum and pleural fluid biochemical analyses have some advantages including but not limited to low cost, short TAT, easy standardisation with less operator or observer variations. Indeed, some pleural fluid and serum markers have shown extremely high diagnostic accuracy in patients with PE; for instance, interleukin-27 (IL-27), ${ }^{12}$ interferon-gamma ${ }^{13}$ and adenosine deaminase (ADA) ${ }^{14}$ pleural fluid levels for tuberculous PE and serum N-terminal pro-brain natriuretic peptide (NT-proBNP) for CHF. ${ }^{415}$ However, for malignant and infectious diseases, the diagnostic accuracy of available markers such as tumour markers, ${ }^{41617}$ procalcitonin $(\mathrm{PCT})^{18}$ and $\mathrm{C}$ reactive protein $(\mathrm{CRP})^{19}$ is unsatisfactory. Therefore, further researches are needed to identify novel markers in PE with increased diagnostic accuracy.

Here, we plan to perform a prospective, double-blind diagnostic trial, named a Study Investigating Markers in PLeural Effusion (SIMPLE). The aim of SIMPLE is to (1) evaluate the diagnostic accuracy of serum and pleural fluid markers when used alone; (2) compare the diagnostic accuracy of two or more markers in a head-to-head manner; (3) verify whether a novel marker can provide added diagnostic information beyond available traditional markers.

\section{METHOD}

\section{Trial registration and foundation}

All subjects, or their guardians, will be provided a full informed consent before inclusion in the study. The study has been registered with the Chinese Clinical Trial Registry platform (http://www.chictr.org.cn/index. aspx). Currently, this study is not supported by any grant; however, it may be supported by one or more grants from the Affiliated Hospital of Inner Mongolia Medical University or the Chinese government in future. The funders will not be involved in study design, sample collection and data analyses.

\section{Subject enrolment and specimen collection}

Subjects who will be admitted to our hospital for an evaluation of the aetiology of the PE will be eligible for enrolment. The presence of PE will be evaluated first by clinical examination and then further confirmed by chest imaging such as CT scan or ultrasound. The exclusion criteria are (1) age less than 18 years; (2) with a known diagnosis of a disease that could cause PE during the last 3 months; (3) pregnancy; (4) refused to sign informed consent; (5) with comorbidities that can prevent pleural fluid collection; (6) subject dies during hospitalisation without collection of pleural fluid and serum specimens; (7) death of a subject during hospital stay before the final diagnosis; (8) patients admitted without PE but developed PE after admission.

Pleural fluid specimen collection will be initiated after obtaining informed consent by the patient.
Approximately 5-10 mL of pleural fluid specimen will be collected in a tube that does not contain any anticoagulant. The specimen will be sent to laboratory within 2 hours and centrifuged at $1200 \mathrm{~g}$ for $10 \mathrm{~min}$. The supernatants of the specimen will then be transferred to 10 Eppendorf tubes $(550 \mu \mathrm{L}$ tube) and immediately frozen at $-80^{\circ} \mathrm{C}$ for later use. A serum sample will be collected from the same patient within 24 hours before or after the pleural fluid collection to be frozen at $-80^{\circ} \mathrm{C}$ if available. A case report form will be used to record demographical and clinical details of the subjects, such as age, sex, side of PE (left-sided, right-sided or two-sided effusion), smoking history, conventional laboratory tests and microbiological findings.

All subjects will be enrolled by a pulmonologist (LY). The subjects will be not consecutively enrolled because they may: (1) refuse to sign the informed consent; (2) be admitted at weekend when LY is not on duty; (3) not be admitted to the Department of Respiratory and Critical Care Medicine of our institution.

The laboratory technician who determines the concentration of investigated markers will be blinded to clinical presentations of the subjects.

\section{Sample size estimation}

As this is not a hypothesis-driven research, we did not estimate the sample size before subjects' enrolment. The study execute time will last from September 2018 to July 2021. It is estimated that 200 to 300 subjects will be enrolled.

\section{Final diagnosis}

This is an observational study that will not affect the further management of the enrolled subjects. The clinicians will decide the further diagnostic, treatment and management independent of this study. The aetiologies of $\mathrm{PE}$ are diverse and the diagnostic criteria for the major diseases are listed in table 1 . The final diagnosis will be made by two researchers independently (LY and Z-DH) and the results of investigated markers will not be known by them when making diagnosis.

Given that approximately $30 \%$ of PEs have more than one aetiology and the most common secondary cause is $\mathrm{CHF},{ }^{20}{ }^{21}$ all patients will be evaluated for concomitant presence of CHF. For some subjects, the differential diagnosis can change during their admission and only the diagnosis at the time of specimen collection will be used. We also realise that a confirmed diagnosis is not possible in all cases with $\mathrm{PE}$ at the time of discharge. This can be due to the fact that some subjects might refuse to receive further diagnostic invasive approaches such as thoracoscopy. The number of these subjects will be recorded and reported. The patients without final diagnosis will be excluded from the final analysis or will be considered as control in the data analysis.

\section{Markers will be investigated in SIMPLE study}

In addition to routinely measured markers (eg, ADA, NT-proBNP), several novel markers will be studied (eg, 
Table 1 Diagnostic criteria for major diseases related to pleural effusion

\begin{tabular}{ll}
\hline Aetiology & Diagnostic criteria \\
\hline Tuberculous & $\begin{array}{l}\text { Identification of Mycobacterium tuberculosis in the sputum, pleural fluid or pleural biopsy specimens, } \\
\text { either by microscopy or by cultures. In some cases with adequate clinical context, the diagnosis } \\
\text { can be made with presence of granuloma in the parietal pleura, good response to anti-tuberculosis } \\
\text { treatment, elevated level of pleural fluid adenosine deaminase or positive nucleic acid amplification tests } \\
\text { (NAATs). }\end{array}$ \\
$\begin{array}{l}\text { Congestive heart } \\
\text { failure (CHF) }\end{array}$ & $\begin{array}{l}\text { Typical clinical picture of CHF including the Framingham score, medical history and physical examination, } \\
\text { the response to diuretic therapy, typical CHF features on chest X-ray, the echocardiographic evidence of } \\
\text { left ventricular systolic dysfunction. }{ }^{153746} 47\end{array}$ \\
\hline $\begin{array}{l}\text { Malignant diseases } \\
\text { Identification of cancer cells in pleural fluid, sputum or bronchoalveolar lavage fluid by cytological } \\
\text { examination, ultrasound or thoracoscopy-guided pleural biopsy. }\end{array}$ & $\begin{array}{l}\text { Typical clinical and radiological evidences of pneumonia, a positive bacterial culture from pleural fluid or } \\
\text { good response to antibiotic therapy. }{ }^{546} \\
\text { effusion }\end{array}$ \\
$\begin{array}{l}\text { Pulmonary } \\
\text { embolism }\end{array}$ & \begin{tabular}{l} 
Computed tomographic pulmonary angiography. ${ }^{48}$ \\
\hline
\end{tabular}
\end{tabular}

soluble Fas ligand, presepsin, pentraxin-3 and IL-27). The serum and fluid markers intended to be investigated are listed in table 2. It should be noted that the decision of whether or not to investigate these markers is greatly determined by the prevalence of target disease as well as statistical power. Novel markers which are not listed in table 2 may also be studied if they showed high accuracy in identifying the aetiologies of PE. In addition, the accuracy of Light criteria in differentiating exudate from transudate will also be studied.

\section{Patient and public involvement}

Figure 1 is a flowchart depicting the study procedure. Subjects who will meet the inclusion and exclusion criteria will be invited to participate in this study. An informed consent will be signed before their participation. All subjects will not be involved in the recruitment and conduct of the study.

Routine serum and pleural fluid analysis will be ordered for these subjects. Pleural fluid specimens will be obtained for routine laboratory analysis, including cell count and differentiation, tumour markers, biochemistry, bacterial culture, Gram staining, cytology and nucleic acid amplification tests (NAAT). These laboratory tests will be ordered by the attending clinicians independent of this study. Approximately $5-10 \mathrm{~mL}$ of pleural fluid specimen will be collected simultaneously for research aims. All fluid and serum specimens will be collected at the time of admission before final diagnosis. The time period between the pleural fluid specimen collection and final diagnosis will be usually within 1 week, except for some subjects who need follow-up and therapy response to make diagnosis. Imaging (CT, MRI, computed tomographic pulmonary angiography), thoracoscopy and bronchoscopy will be ordered if necessary. The results of markers will be disseminated to the subjects via email or telephone on request after the completion of the study.

\section{Ethics and dissemination}

The results of SIMPLE will be submitted to international scientific peer-reviewed journals or conferences in laboratory medicine or respiratory medicine, thoracic diseases.

\section{Statistical analysis}

Normal distribution of continuous data will be tested by Kolmogorov-Smirnov test. For the data with normal distribution, independent t-test or one-way ANOVA will be used for comparison. Otherwise, Mann-Whitney or Kruskal-Wallis tests will be used. Chi-square test will be used to compare categorised data. Receiver operating characteristics (ROC) curve analysis will be used to evaluate the diagnostic accuracy of the investigated markers. Area under ROC curve (AUC) will be used to estimate the overall diagnostic accuracy of markers. AUCs of markers will be compared by the approach proposed by DeLong et $a l^{22}$ The optimal threshold will be determined by the method proposed by Pepe et $a t^{23}$ or maximum Youden index. When evaluating the diagnostic accuracy of a

Table 2 Markers will be investigated in SIMPLE study

\begin{tabular}{ll}
\hline Target disease & Markers \\
\hline Congestive heart failure & Mid-regional pro-atrial natriuretic peptide (MR-proANP) \\
Tuberculous pleurisy & Soluble Fas ligand; interleukin 27 (IL-27); C-X-C motif chemokine receptor 3 (CXCR3) ligands \\
Malignant diseases & Soluble B7-H4; human epididymis 4 (HE4); cancer ratio; Dickkopf-1 (DDK1) \\
Parapneumonic effusion & Presepsin; pentraxin-3 \\
\hline
\end{tabular}

SIMPLE, Study Investigating Markers in PLeural Effusion. 


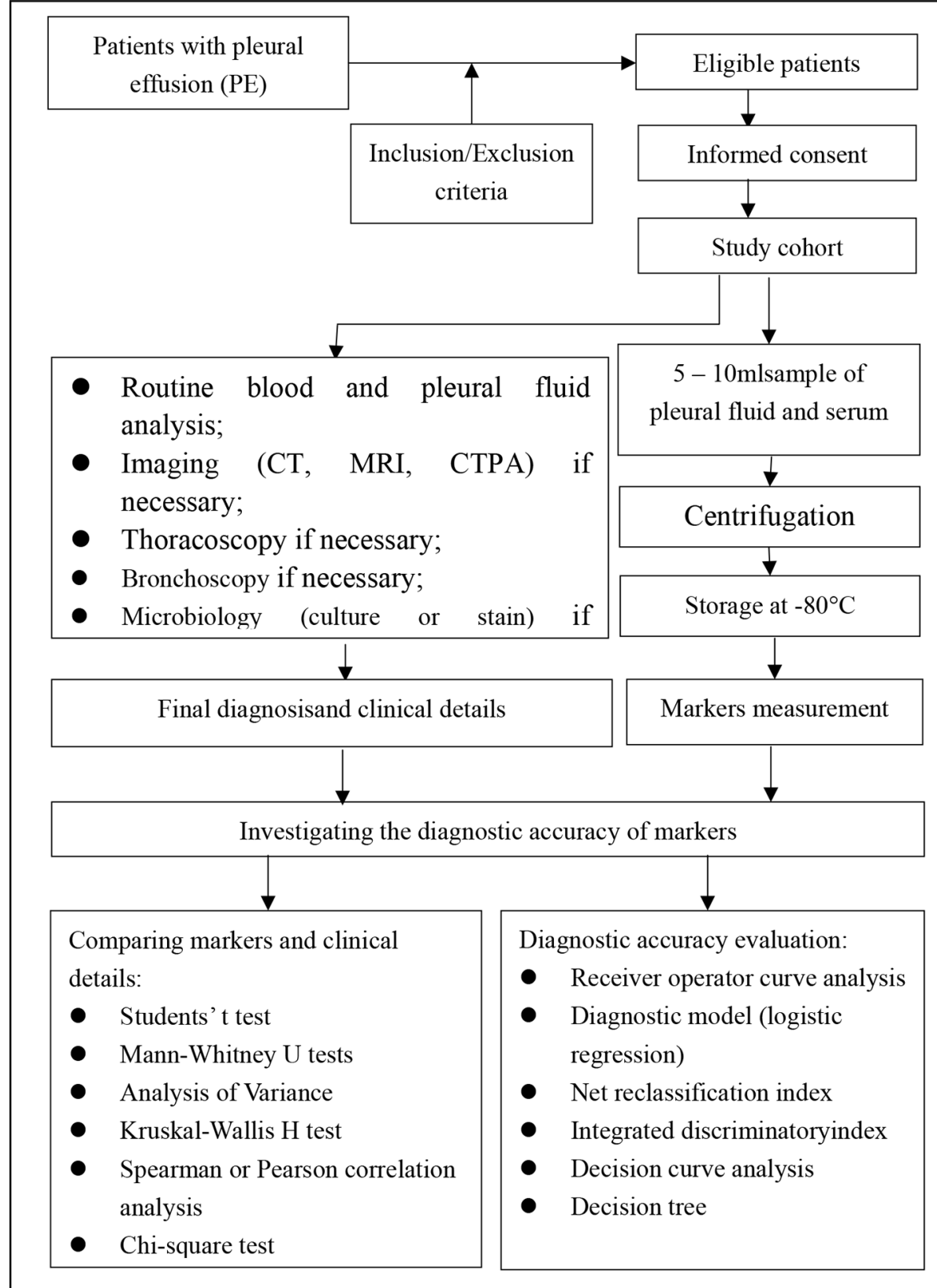

Figure 1 Flowchart of study procedure.

marker for a given disease, the subjects with this disease will be categorised into a disease group, regardless of whether other aetiologies co-occur. Multivariable logistic regression model, net reclassification index (NRI) and integrated discriminatory index (IDI) will be used to evaluate whether a given marker provides added diagnostic information ${ }^{2425}$ beyond conventional diagnostic tools and clinical details (eg, side information, age, sex, smoking history). Decision tree approach and decision curve analysis (DCA $)^{26}$ will be created to evaluate the preferred diagnostic strategy. All analyses will be performed with SPSS V.18.0 (IBM Corporation), Sigmaplot V.12.0 (Systat Software, Inc., San Jose, California, USA), Graphpad Prism V.6.0 (GraphPad Software, La Jolla, California, USA) and R (http://www.r-project.org).

\section{DISCUSSION}

Multiple new diagnostic markers have been identified in the evaluation of $\mathrm{PE}$ with the advancement in omics approach and basic research. Therefore, it is valuable to evaluate the diagnostic accuracy of these markers rigorously. Although several studies have been performed on this topic, ${ }^{12} 2728$ the result of these studies need to be validated. This is because that the diagnostic accuracy of a given marker may be affected by the disease spectrum of a study cohort. ${ }^{29}$ Besides, majority of previously published studies evaluated only the diagnostic accuracy of single marker and did not compare it with other promising markers. Furthermore, whether multimarker strategy can improve the diagnostic accuracy remains largely unknown. 
Compared with previous studies, SIMPLE study has some strength. First, this is a registered, prospective, double-blind study. Therefore, the results of this study are more reliable. Second, majority of the previous studies did not consider the subjects with multiple aetiologies of PE and this issue will be considered by SIMPLE study. Third, only limited studies have investigated whether a novel marker could provide added diagnostic information beyond traditional markers. In SIMPLE study, we will investigate this issue with IDI and NRI, although they have some shortcomings. ${ }^{30-33}$

Multiple potential serum and fluid markers will be investigated in the SIMPLE study. Previous studies have indicated that presepsin is a useful diagnostic marker for bacterial infection ${ }^{34}{ }^{35}$; nevertheless, it remains unknown whether presepsin in serum or pleural fluid is useful for the diagnosis of parapneumonic effusion. Serum mid-regional pro-atrial natriuretic peptide (MR-proANP) has been reported to have high diagnostic accuracy for $\mathrm{CHF}^{36}$ However, only one study has investigated the diagnostic accuracy of MR-proANP in PE caused by CHF, ${ }^{37}$ and the results of this study need to be validated. In addition, some novel markers, such as soluble Fas ligand ${ }^{38}$ and IL-2 $7^{12}$ for tuberculous pleurisy, soluble B7-H4 ${ }^{39}$ and human epididymis $4^{40}$ for malignant effusion, will also be studied. The results of SIMPLE study will be reported in accordance with the Standards for Reporting of Diagnostic Accuracy Studies guideline. ${ }^{41}$ For researches with multivariable prediction model, the report will comply with Transparent Reporting of a Multivariable Prediction Model for Individual Prognosis or Diagnosis statement. ${ }^{42}$

SIMPLE study has some limitations. First, this is a single centre study and representativeness of the study cohort is a limitation. Second, because it is not ethical to let all subjects receiving all diagnostic tools once a diagnosis has been made, partial verification bias cannot be avoided. Indeed, establishing one diagnosis does exclude other aetiologies. Third, the prognostic value of markers will not be evaluated in this study.

Taken together, SIMPLE study is a prospective, doubleblind diagnostic study that aims to investigate the diagnostic accuracy of serum and pleural fluid markers. Although it has some limitations, we believe that this study will provide a new insight into the PE aetiological field.

Acknowledgements We thank the clinicians in the Department of Respiratory and Critical Care Medicine and technicians in the Department of Laboratory Medicine for their support. We thank Dr Hemant Goyal MD FACP from Mercer University School of Medicine for manuscript editing.

Contributors Z-DH conceived and designed the study; LZ, P-HO and PL provided administrative support; LZ, P-HO, PL, LY and Y-QH drafted the manuscript. Z-DH critically revised the manuscript. All authors approved the final version of the manuscript.

Funding The authors have not declared a specific grant for this research from any funding agency in the public, commercial or not-for-profit sectors.

Competing interests None declared.

Patient consent for publication Obtained.
Ethics approval This study has been approved by the Ethic Committee of the Affiliated Hospital of Inner Mongolia Medical University (NO: 2018011).

Provenance and peer review Not commissioned; externally peer reviewed.

Open access This is an open access article distributed in accordance with the Creative Commons Attribution Non Commercial (CC BY-NC 4.0) license, which permits others to distribute, remix, adapt, build upon this work non-commercially, and license their derivative works on different terms, provided the original work is properly cited, appropriate credit is given, any changes made indicated, and the use is non-commercial. See: http://creativecommons.org/licenses/by-nc/4.0/.

\section{REFERENCES}

1. Porcel JM, Esquerda A, Vives M, et al. Etiology of pleural effusions: analysis of more than 3,000 consecutive thoracenteses. Arch Bronconeumol 2014;50:161-5.

2. Wang XJ, Yang Y, Wang Z, et al. Efficacy and safety of diagnostic thoracoscopy in undiagnosed pleural effusions. Respiration 2015;90:251-5.

3. Light RW, Macgregor MI, Luchsinger PC, et al. Pleural effusions: the diagnostic separation of transudates and exudates. Ann Intern Med 1972;77:507.

4. Zhou Q, Ye ZJ, Su Y, et al. Diagnostic value of N-terminal pro-brain natriuretic peptide for pleural effusion due to heart failure: a metaanalysis. Heart 2010;96:1207-11.

5. Porcel JM, Azzopardi M, Koegelenberg CF, et al. The diagnosis of pleural effusions. Expert Rev Respir Med 2015;9:801-15.

6. Beaudoin S, Gonzalez A V. Evaluation of the patient with pleural effusion. Can Med Assoc J 2018;190:E291-5.

7. Assawasaksakul T, Boonsarngsuk V, Incharoen P. A comparative study of conventional cytology and cell block method in the diagnosis of pleural effusion. J Thorac Dis 2017;9:3161-7.

8. Conde MB, Loivos AC, Rezende VM, et al. Yield of sputum induction in the diagnosis of pleural tuberculosis. Am J Respir Crit Care Med 2003;167:723-5.

9. Valdés L, Alvarez D, San José E, et al. Tuberculous pleurisy: a study of 254 patients. Arch Intern Med 1998;158:2017.

10. Shivakumarswamy U, Arakeri SU, Karigowdar MH, et al. Diagnostic utility of the cell block method versus the conventional smear study in pleural fluid cytology. J Cytol 2012;29:11.

11. Kastelik JA. Management of malignant pleural effusion. Lung 2013;191:165-75.

12. Wang $W$, Zhou Q, Zhai K, et al. Diagnostic accuracy of interleukin 27 for tuberculous pleural effusion: two prospective studies and one meta-analysis. Thorax 2018;73:240-7.

13. Jiang J, Shi HZ, Liang QL, et al. Diagnostic value of interferongamma in tuberculous pleurisy: a metaanalysis. Chest 2007;131:1133-41.

14. Liang QL, Shi HZ, Wang K, et al. Diagnostic accuracy of adenosine deaminase in tuberculous pleurisy: a meta-analysis. Respir Med 2008;102:744-54.

15. Han ZJ, Wu XD, Cheng JJ, et al. Diagnostic accuracy of natriuretic peptides for heart failure in patients with pleural effusion: a systematic review and updated meta-analysis. PLoS One 2015;10:e0134376.

16. Hu ZD, Liu XF, Liu XC, et al. Diagnostic accuracy of osteopontin for malignant pleural mesothelioma: a systematic review and metaanalysis. Clin Chim Acta 2014;433:44-8.

17. Liang QL, Shi HZ, Qin XJ, et al. Diagnostic accuracy of tumour markers for malignant pleural effusion: a meta-analysis. Thorax 2008;63:35-41.

18. He C, Wang B, Li D, et al. Performance of procalcitonin in diagnosing parapneumonic pleural effusions. Medicine 2017;96:e7829.

19. Zou MX, Zhou RR, Wu WJ, et al. The use of pleural fluid procalcitonin and C-reactive protein in the diagnosis of parapneumonic pleural effusions: a systemic review and meta-analysis. Am J Emerg Med 2012;30:1907-14.

20. Bintcliffe OJ, Hooper CE, Rider IJ, et al. Unilateral pleural effusions with more than one apparent etiology. A prospective observational study. Ann Am Thorac Soc 2016;13:1050-6.

21. Walker S, Maskell N. Identification and management of pleural effusions of multiple aetiologies. Curr Opin Pulm Med 2017;23:339-45.

22. DeLong ER, DeLong DM, Clarke-Pearson DL. Comparing the areas under two or more correlated receiver operating characteristic curves: a nonparametric approach. Biometrics 1988;44:837-45 http://www.ncbi.nlm.nih.gov/pubmed/3203132.

23. Pepe MS, Janes $\mathrm{H}$, Li Cl, et al. Early-phase studies of biomarkers: what target sensitivity and specificity values might confer clinical utility? Clin Chem 2016;62:737-42. 
24. Moons KG, de Groot JA, Linnet K, et al. Quantifying the added value of a diagnostic test or marker. Clin Chem 2012;58:1408-17.

25. Pencina MJ, D'Agostino RB, D'Agostino RB, et al. Evaluating the added predictive ability of a new marker: from area under the ROC curve to reclassification and beyond. Stat Med 2008;27:157-72.

26. Vickers AJ, Elkin EB. Decision curve analysis: a novel method for evaluating prediction models. Med Decis Making 2006;26:565-74.

27. Chung $\mathrm{W}$, Jung $\mathrm{Y}$, Lee $\mathrm{K}$, et al. CXCR3 ligands in pleural fluid as markers for the diagnosis of tuberculous pleural effusion. Int $J$ Tuberc Lung Dis 2017;21:1300-6.

28. Pass HI, Levin SM, Harbut MR, et al. Fibulin-3 as a blood and effusion biomarker for pleural mesothelioma. $N$ Engl J Med 2012;367:1417-27.

29. Linnet K, Bossuyt PM, Moons KG, et al. Quantifying the accuracy of a diagnostic test or marker. Clin Chem 2012;58:1292-301.

30. Pepe MS, Fan J, Feng Z, et al. The net reclassification index (NRI): a misleading measure of prediction improvement even with independent test data sets. Stat Biosci 2015;7:282-95.

31. Gerds TA, Hilden J. Calibration of models is not sufficient to justify NRI. Stat Med 2014;33:3419-20.

32. Hilden J. Commentary: On NRI, IDI, and "good-looking" statistics with nothing underneath. Epidemiology 2014;25:265-7.

33. Hilden J, Gerds TA. A note on the evaluation of novel biomarkers: do not rely on integrated discrimination improvement and net reclassification index. Stat Med 2014;33:3405-14.

34. Wu J, Hu L, Zhang G, et al. Accuracy of presepsin in sepsis diagnosis: a systematic review and meta-analysis. PLoS One 2015;10:e0133057.

35. Zhang J, Hu ZD, Song J, et al. Diagnostic value of presepsin for sepsis: a systematic review and meta-analysis. Medicine (Baltimore) 2015;94:e2158.

36. Hu Z, Han Z, Huang Y, et al. Diagnostic power of the mid-regional pro-atrial natriuretic peptide for heart failure patients with dyspnea: a meta-analysis. Clin Biochem 2012;45:1634-9.

37. Porcel JM, Bielsa S, Morales-Rull JL, et al. Comparison of pleural $\mathrm{N}$-terminal pro-B-type natriuretic peptide, midregion pro-atrial natriuretic peptide and mid-region pro-adrenomedullin for the diagnosis of pleural effusions associated with cardiac failure. Respirology 2013;18:540-5.

38. Wu SH, Li CT, Lin $\mathrm{CH}$, et al. Soluble Fas ligand is another good diagnostic marker for tuberculous pleurisy. Diagn Microbiol Infect Dis 2010;68:395-400.

39. Xu C, Qian L, Yu L, et al. Evaluation of serum and pleural levels of soluble B7-H4 in lung cancer patients with pleural effusion. Biomarkers 2015;20:271-4.

40. Elsammak MY, Attia A, Hassan HA, et al. Evaluation of pleural fluid human epididymis 4 (HE4) as a marker of malignant pleural effusion. Tumour Biol 2012;33:1701-7.

41. Bossuyt PM, Reitsma JB, Bruns DE, et al. STARD 2015: an updated list of essential items for reporting diagnostic accuracy studies. Clin Chem 2015;61:1446-52.

42. Collins GS, Reitsma JB, Altman DG, et al. Transparent Reporting of a Multivariable Prediction Model for Individual Prognosis or Diagnosis (TRIPOD): the TRIPOD statement. BMJ 2015;350:97594.

43. Zhai K, Lu Y, Shi HZ. Tuberculous pleural effusion. J Thorac Dis 2016;8:E486-94.

44. Trajman A, Pai M, Dheda K, et al. Novel tests for diagnosing tuberculous pleural effusion: what works and what does not? Eur Respir J 2008;31:1098-106.

45. Porcel JM. Advances in the diagnosis of tuberculous pleuritis. Ann Transl Med 2016;4:282.

46. Kolditz M, Halank M, Schiemanck CS, et al. High diagnostic accuracy of NT-proBNP for cardiac origin of pleural effusions. Eur Respir J 2006;28:144-50.

47. Liao H, Na MJ, Dikensoy O, et al. Diagnostic value of pleural fluid $\mathrm{N}$-terminal pro-brain natriuretic peptide levels in patients with cardiovascular diseases. Respirology 2008;13:53-7.

48. Konstantinides S V, Torbicki A, Agnelli G, et al. ESC Guidelines on the diagnosis and management of acute pulmonary embolism. Eur Heart J 2014;2014:3033-80. 